https://doi.org/10.18485/kud_kiaz.2019.ch13

\author{
Nigar Valiyeva, $\mathrm{PhD}$ \\ Azerbaijan University of Languages
}

\title{
DEVELOPMENT OF LINGUISTICS IN THE CONTEXT OF GLOBALIZATION
}

\begin{abstract}
SUMMARY
Nowadays it is an irrefutable fact that global English is the agile, transactional language, it has such kind of polyphony and diplomacy that keeps the pulse of modern world, at the same time it is in the ascendant and influences on the basic word stock of all world languages, including the Azerbaijani language. And during the process of globalization a such affection must not be so much. We, Azerbaijanians must to protect our mother tongue of that kind of impact and as the result of it, from the needless borrowings. Azerbaijan is the country of the ancient history and culture, has a rich national language, and realizes a subtile policy. And we must defend our historical past, support our present culture and develop our future national consciousness.
\end{abstract}

Key words: world's communication, Linguistics' development, the literary language, language teaching, cultural diplomacy, discourse analysis.

Falling in the reality that Modern English is truly the global language as the main means of world's communication, during the period of globalization in our modern society the problem of the national language, and especially of the literary language and basic word stock is an actual.

Thus, it can be concluded that there is a very close relationship between language and culture in general, and a specific language and its culture in particular. That is, culture 
has a direct effect on language. In fact, the two issues are closely correlated and interrelated. Language is the symbolic presentation of a nation or a specific community. In other words, language is the symbolic presentation of a culture. So, we must keep, develop and generalize the use of the national language as well as Azerbaijani national culture.

Thus, "State Program on Usage of the Azerbaijani Language and development of Linguistics in Accordance with the Current (Modern) Requirements in the Context of Globalization" approved by the 10-th April 2013 resolution of the President of the Azerbaijan Republic is a particular historical event. State Program on Usage of the Azerbaijani language includes the following duties: 1) A development, defense, broad usage in the electron space of the Azerbaijani language answering to the appropriate demands of modern times during globalization and establishment of the mechanism of Linguistics' development in the country; 2) A perfection of training of high-specialized community in the sphere of Linguistics; 3) Taking into a consideration the modern development of the world Linguistics to determine the directions of the scientific investigations; 4) An elaboration of the cooperation with the world leading scientific centers in the field of Linguistics; 5) A coordination and improvement of the issues of the language and education; 6) A guarantee of scientific participation of the linguists in the formation of the modern information and communication technologies; 7) A learning of the ancient languages' history in order to analyze fundamentally the history of language, especially literary language and culture; 8) A retrofit of the legislative base covering the language's development and an improvement of the literary language's norms; 9) An enhancement of the language and speech' culture; 10) A systematization of the basic word stock of the Azerbaijani language and its grammatical norms; 11) A studying of language's situations and language's relations in the Azerbaijani Republic.

A national concept's sphere consists of the complex of individual, factional, sectional, class and universal concepts, 
i.e. concepts, having panhuman value. To a number of universal concepts belong such base concepts, such as "motherland, mother, family, freedom, love, faith, and friendship". On their basis the national cultural values are formed and also fundamental universals as "time, space, causality" and so on. So, the existence of general, universal concepts provides the possibility of common ground and public relations between peoples that is so important in the modern world. We must develop the national consciousness as it consists of the complex of individual, factional, sectional, class and universal concepts, i.e. concepts, having panhuman value. Because the existence of the universal concepts provides the possibility of common ground and public relations between peoples, that is so important in the modern world.

Today the cultural diplomacy is widely used with the purpose to develop the intercultural relations in the international intercourse. An outreach of the Azerbaijani culture in the international scope, an awareness of the world's commonality, the development of the intellectual culture in the community, the realization of the intellectual-cultural struggle in the appropriate form that we met in the abroad, an active colleaguesmanship of the scientists in such processes are the relevant orientations and courses of the cultural diplomacy of the Azerbaijan Republic.

Nowadays there are the following characteristic features of our modern Azerbaijani society: the ancietry, richness, a tendency of the dynamical development of the Azerbaijani cultural values, the activity of the cultural processes, an interest to the civilized values, and the existence of the historical and modern practices in the sphere of the unification of the Islamic and European values, the tolerance. The Azerbaijan Republic as the synthesis of the cultures of the East and West is as the member of the European Society, so the member of the UNESCO and ISESCO.

Analyzing the ways of the enrichment of the basic word stock of the Azerbaijani language in the period of the 
independence we knew that the means of mass media really play a great role and have the multilateral function in the society. A propagating of the literary language, a spreading of the objective information, an increasing of the education, an acquaintance with the various cultures and their learning, an amusement, the upbuilding of the nexus between world's population, the learning of the foreign languages, and so on became the order of the day. If all this would be used in the appropriate form, the means of mass media play the supporting role in the way of the development of the forwarding population.

It is necessary to notice that if we have discussed theories of the pragmatic interpretation of language, we must investigate how people create meaning and make sense of what is said in specific circumstances. The fact that meaning is not constructed from the formal language of the message alone is crucial in explaining what it is that makes people perceive some stretches of language as coherent discourse and others as disconnected jumbles. It is also important for the successful teaching and learning of foreign languages.

The importance of pragmatic theories in language learning is really twofold. Firstly, the divergence of function and form means that we cannot rely upon teaching only form. In production, learners need to choose the words which most suitably realize their intention, and this does not always entail the most closely related form. In reception of language, given the human penchant for indirection, they also need to be able to move from the form to the function. There are times when making language function effectively is more important than producing perfectly pronounced, grammatically correct sentences.

Secondly, the linking of form to function may help learners to orientate themselves within a discourse. All learners of a foreign language are familiar with the disturbing sensation of understanding every word, and the literal meaning, but somehow missing the point. The underlying structure of the discourse may be a progression of functional units, and a 
breakdown in pragmatic interpretation may easily lead to a learner losing his or her way. We shall need to go further in examining how functional units interact to create discourse, and how the learner may be guided through them.

These two points raise the issue of the extent to which pragmatic interpretation and discourse structure are culture specific, and the extent to which they need to be or can be taught. In order to "do things with words" either actively as language producers or passively, as language understanders, we clearly need more tools than the formal language system, though we do need that too. The needs of the language user might be represented as:

U S E R

\begin{tabular}{|c|c|c|c|}
\hline Language system & Paralanguage & Knowledge & Reasoning \\
\hline pronunciation & voice & globalization \\
grammar & face & $\begin{array}{c}\text { cultural } \\
\text { world }\end{array}$ & $\begin{array}{c}\text { intercultural } \\
\text { communication }\end{array}$ \\
\hline vocabulary & body & goal & goal \\
\hline goal & goal & goal
\end{tabular}

Traditionally, language teaching has concentrated only on the three levels of the formal language system - pronunciation, grammar, vocabulary and the way in which they function within the sentence, on the assumption that other aspects of communication will follow fairly automatically.

It remains true, that the formal system of a foreign language is very obviously different from that of the learner's first language, that it therefore forms the basis of any full communication and that it needs to be acquired in some way. However, it is not all that is needed for communication. In our search for the forces which create coherence, we have examined some of the other factors in communication.

It is useful to mention the importance of world knowledge and social knowledge in the production and reception of 
discourse. Existing knowledge in the receiver of a message, and the correct assessment of the extent of that knowledge by the sender, are essential for successful communication.

In recent years the role of knowledge in discourse production and comprehension has been significantly stimulated by findings in the field of "artificial intelligence", which, among other endeavors, attempts to program computers to produce and understand discourse. As we have seen, this involves far more than the language being used; it involves pre-existent knowledge of the world. Artificial intelligence tries to understand how this knowledge and language interact, and to reproduce the process in computers.

For discourse analysis, the most important idea to come out of the field of artificial intelligence is that of knowledge "schemata". These are mental representations of typical situations, and they are used in discourse processing to predict the contents of the particular situation which the discourse describes. The idea is that the mind, stimulated by key words or phrases in the text, or by the context, activates a knowledge schema, and uses it to make sense of the discourse.

To program a computer to understand a discourse, artificial intelligence researchers need to reproduce this process, and to give computers both the necessary language knowledge, and the necessary schemata. The suggestion is that computers can be programmed to process discourse in a similar way to human beings, though the complexity of human language competence and human knowledge are far greater than those of any existing computer.

Considering the complexity of the interaction of minds, language, and the world, the description is highly simplified. Actual discourse is unlikely to be interpretable with reference to a single schema. In reality the mind must activate many schemata at once, each interacting with the other. It must be capable of moving rapidly from one to another, of using more than simultaneously, of focusing on a sub-schema. It must be capable of building new schemata, and of ditching old ones. 
Schemata need not be limited to unordered catalogues of people and things within a stereotyped situation, or stereotyped sequences of events and things within a stereotyped situation, or stereotyped sequences of events telling us what is likely to happen next.

They may also predict stereotypical roles and relationships of participants, or they can be stereotypical text types, predicting plot structure or conversational development. Participants in conversation have certain, no doubt highly culture-bound, assumptions about possible courses for a conversation, length and type of turn, total duration and so on. Less reciprocal discourse will also activate schemata.

When we watch a TV police thriller, we match it against a schema which contains certain characters, playing particular roles in certain sequences of events, in a plot with certain episodes and a particular outcome. Our pleasure or displeasure depending on our taste or mood will derive either from the high degree of conformity of the individual example to the schema, or from its divergence.

As it is known, schemata are data structures, representing stereotypical patterns, which we retrieve from memory and employ in our understanding of discourse. The successful communicator selects just those features which differ from this schema, enabling the receiver to adjust it and to bring it closer to the individual instance which is being described. Schema theory can go a long way towards explaining the sender's choice and arrangement of information in communication. It can also elucidate some of the vaguer notions of pragmatic theory. One of Herbert Paul Grice's maxims tells us to "be relevant", but it does not attempt to explain the notion of relevance. Speech act theory, by attempting to single out the pieces of shared knowledge which enable us to interpret the function of what is said, also assumes that we can distinguish which factors in the situation are relevant, but again it does nothing to explain how we distinguish the relevant from the irrelevant. The idea that conversation proceeds according to a 
principle, known and applied by all human beings, was first proposed in a limited form by the philosopher Herbert Paul Grice (2005), who put forward what he described as the cooperative principle.

According to this principle, we interpret language on the assumption that its sender is obeying four maxims. We assume speaker is intending to be true (the maxim of quality), brief (the maxim of quantity), relevant (the maxim of relevance) and clear (the maxim of manner). Using this assumption, combined with general knowledge of the world, the receiver can reason from the literal, semantic meaning of what is said to the pragmatic meaning and induce what the sender is intending to do with his or her words.

In 1986 Dan Sperber and Deirdre Wilson have used a model of communication which is very closely related to schema theory to explain the concept of relevance. Human minds, they say, have a long-term aim: to increase their knowledge of the world. In each encounter with discourse, we start with a set of assumptions, whose accuracy we seek to improve.

Information is relevant when it has a significant effect on our assumptions, in other words, when it will allow us to alter our knowledge structures to give us a more accurate representation of the world. On the other hand, successful communication must work within the framework of the receiver's existing knowledge; it must not make too many demands. So, relevant information adjusts our picture of the world very subtly. It is, say Sperber and Wilson, information which yields the greatest change in our knowledge for the least processing effort. Successful communication gives us new information, but works within the framework of the receiver's assumptions.

Schemata allow human communication to be economical. It would be hard to see how communication could take place if we could not take some sort of mutually shared knowledge for granted, if every discourse had to begin from scratch. 
The idea of pre-existing schemata will thus explain Grice's other maxims too. If we provide information which is already known to the receiver, then we are too long-winded; if we take knowledge for granted, we are too brief. In either case we violate the maxim of brevity. Communication also suffers when people make false assumptions about shared schemata, and it is then that they cease to "be clear". Lastly, our perception of the truth of discourse is also a comparison of the schemata it evokes its assumptions and our own.

Misjudgments and mismatches of schemata are particularly likely when people try to communicate across cultures and across languages. The resulting misunderstandings are endemic in the foreign language classroom. For this reason schema theory is of as great importance in language teaching as it is discourse analysis.

We also know how knowledge of the world or of the culture enables people to make their language function as they intend and to understand how others do the same to them. To connect their knowledge with the language system people use reasoning and pragmatic theories go some way towards explaining how people reason their way from the form to the function and thus construct coherent discourse from the language they receive.

What we need to decide as language teachers is the degree to which other components of communication need teaching. All human beings have reasoning power, world knowledge and knowledge of at least one culture, but the divisions between these categories and the nature of their contents are not always clear. How far do conversational principles and the interpretation of speech acts proceed differently in different cultures, for example?

We also need to help learners integrate the components of communication one with another. It is no good teaching them as discrete units and hoping that the learner, suddenly faced with a communicative situation, will be able to integrate them all with immediate success. Whatever cultural variation 
there may be in pragmatic interpretation, we may be sure that its interaction with form is language specific. It does need teaching, though we must be careful not to go to the opposite extreme, as many courses do, and patronizingly treat adult learners like new-born babes. They bring with them immense reasoning power, knowledge of the world, and a sophisticated skill at implementing through their own language and culture the complex needs of all humans, to relate to others, and to act with them.

The pragmatic theories we have examined leave a number of unanswered questions, and they are in need of considerable extension before they can be fruitfully applied to discourse analysis and language teaching. It is not always clear, for example, where the context of an utterance ends (Guy Cook, 1986), and even when that is established we are still left with the vagueness of the central concept of relevance.

Another weakness is the implicit assumption that underlying meaning can always be formulated in words. Speech act theory assumes that there is one neat, verbally expressible illocution to each locution. The theories of pragmatic language use are from philosophy rather than linguistics, and the examples used are invented and stylized. They concern spoken discourse in which sender and receiver interact with each other rapidly, and they tend to be short and deal with a few turns at most. This is not a criticism of the theories in themselves, but if discourse analysis is to incorporate them, and to demonstrate their relevance to the language learner, it will need to test their value in interpreting language which has actually occurred, to select what is relevant from context rather than invent a few elements of it, to account for writing as well as speech, and to account for discourse where there is no constant feedback from the receiver who may not even be present. And it will need to deal with long stretches of language, rather than handfuls of utterances.

When we talk about people following the co-operative principle, this does not mean that they can consciously and 
explicity formulate it to themselves. It means rather that people act as though they know the principle just as they act as though they know the rules of grammar, though very few people can even begin to formulate them, and nobody can formulate them completely.

Trying to understand the process by which two or more people come together through text to create discourse and thus communicate can be a very stimulating and exciting investigation. But there are also times when it can seem depressing. Increasingly, we seem to be talking about the unity and meaningfulness of discourse in terms of conformity: to another person's view of the world, to shared stereotypes.

If communication is characterized as a successful attempt to alter the mental state of another human being, it seems that the most successful communication will take place where there is already a considerable coincide between mental states, and the alteration achieved is only minimal. People who see the world differently, and therefore need to communicate, both for mutual education and to avoid conflict, may seem the least likely to be able to do so.

What happens to those who step outside the predictable patterns and regularities? Some are vilified and some are glorified. Some are called mad, disturbed, maladjusted, rebellious, even criminal; others are called individualists, poets, comedians, philosophers. It is easy to escape this issue by saying that the discourses of the two groups have little in common. But discourse analysis should teach us that it is as likely to be our attitude to what they say that categorizes them. Yet however we may judge deviation, whether negatively or positively, being a social outsider is very much a case of non-conformity to the norms and regularities of discourse structure.

Language learners are social outsiders of a different kind, standing outside one community by virtue of belonging to another. They may fail to understand or to make themselves understood because they lack the social knowledge which 
enables them to make text into discourse in the language they are learning. They may come out with oddities, and again we may judge this negatively or positively. The discourse strategies of a foreign speaker may seem refreshing exactly because they do not conform to conventions of the culture whose language they are learning. On the other hand they may cause serious misunderstanding and breakdown of communication.

The task of the language teacher is a difficult one: to facilitate a degree of socialization which will enable learners to send and receive text as discourse, while also guarding their right to be different and to enrich others through that difference, bringing to the language they are learning the wealth of their own individuality and culture. As in the case of deviation within the social group: we do not have to judge difference negatively. Success in communication depends as much upon the receiver as on the sender. Between speakers of different languages it depends as much upon the native speaker as on the foreign learner.

Nowadays it is an irrefutable fact that global English is the agile, transactional language, it has such kind of polyphony and diplomacy that keeps the pulse of modern world, at the same time it is in the ascendant and influences on the basic word stock of all world languages, including the Azerbaijani language. And during the process globalization a such affection must not be so much.

We, Azerbaijanians must to protect our mother tongue of that kind of impact and as the result of it, from the needless borrowings. Azerbaijan is the country of the ancient history and culture, has a rich national language, and realizes a subtile policy. And we must defend our historical past, support our present culture and develop our future national consciousness. The study of relationship between English language proficiency, employment and success of graduates in the Azerbaijani Republic in the interface of globalization, the establishment how English language skills influence on 
the employment mechanism in the Azerbaijani job market for our native graduates will be carried out following approach as its overall aim is to understand the role of English language skills of universuty graduates in determining the empoyment opprtunities and carrer prospects of Azerbaijani graduates.

The research findings may inform educational policy planners, teacher educators, teachers, employers and career advisers to identify the appropriate English language learning programmes that support increased employability through English. The above given contemplation allows to make a conclusion that the process of globalization is permanent. Under the circumstances the era of globalization has at least two tends regarding its cultural aspect development. On the one hand, globalization is changing the traditional lifestyles of people. But on the other hand, some adaptation and protecting functions of each culture are generated, so the process of globalization takes an extremely controversial format. Within the bounds of intercultural communication, some common values and ideals (tolerance, equality of traditions, ethics and politics of responsibility) are being formed. However, the process of creation of commonalities within communicational interaction is not always smooth. For example, such universal values as human rights, which were accepted by western scholars as basic values, turn out to be incompatible with the political and cultural customs of many eastern countries.

Taking into consideration the reality of mega-society in order to prevent such incompatibilities, countries must find points of contact in which the principles of globalization do not contradict customs and traditions of these countries. Then, as we view it, the points of mutual contact should be found. In cases when it seems impossible to find points of mutual contact, countries should demonstrate tolerance and respect to each other. In this connection we can declare that the future of humankind depends only on us and on our actions towards each other. And understanding this is one of many steps which mankind must take in order to prosper together in peace. 


\section{References:}

Cook, Guy. (1986) Problems and solutions in the transcription of context for discourse analysis, RecherchesasnglaisesetNordeAmericain es XIX, p.113-131.

Grice, Herbert Paul. (2005) Logic and Conversation, The Theory of Conversational Implicature. Oxford, Oxford UnversityPress.

Sperber, Dan \& Wilson, Deirdre.(1986) Relevance: Communication and Cognition, Oxford, UK: Blackwell.

Veliyeva, Nigar. (2011) Actual Problems of Language Typology. Azerbaijan, Baku: Science \& Education.

\section{PЕЗЮМЕ}

В настоящее время неопровержимым фактом является то, что глобальный английский язык является наиболее употребляемым, языком бизнеса, он обладает такой полифонией и дипломатией, которая поддерживает пульс современного мира, в то же время он является господствующим языком и влияет на основной словарный запас всех мировых языков, в том числе и азербайджанского языка. И в процессе глобализации такого влияния не должно быть так много. Мы, азербайджанцы, должны защитить свой родной язык от такого рода воздействий и, как следствие этого, от ненужных заимствований. Азербайджан является страной древней истории и культуры, имеет богатый национальный язык и проводит свою политику. И мы должны защищать наше историческое прошлое, поддерживать нашу нынешнюю культуру и развивать наше будущее национальное самосознание.

Ключевые слова: мировая коммуникация, развитие языкознания, литературный язык, преподавание языка, культурная дипломатия, анализ дискурса. 